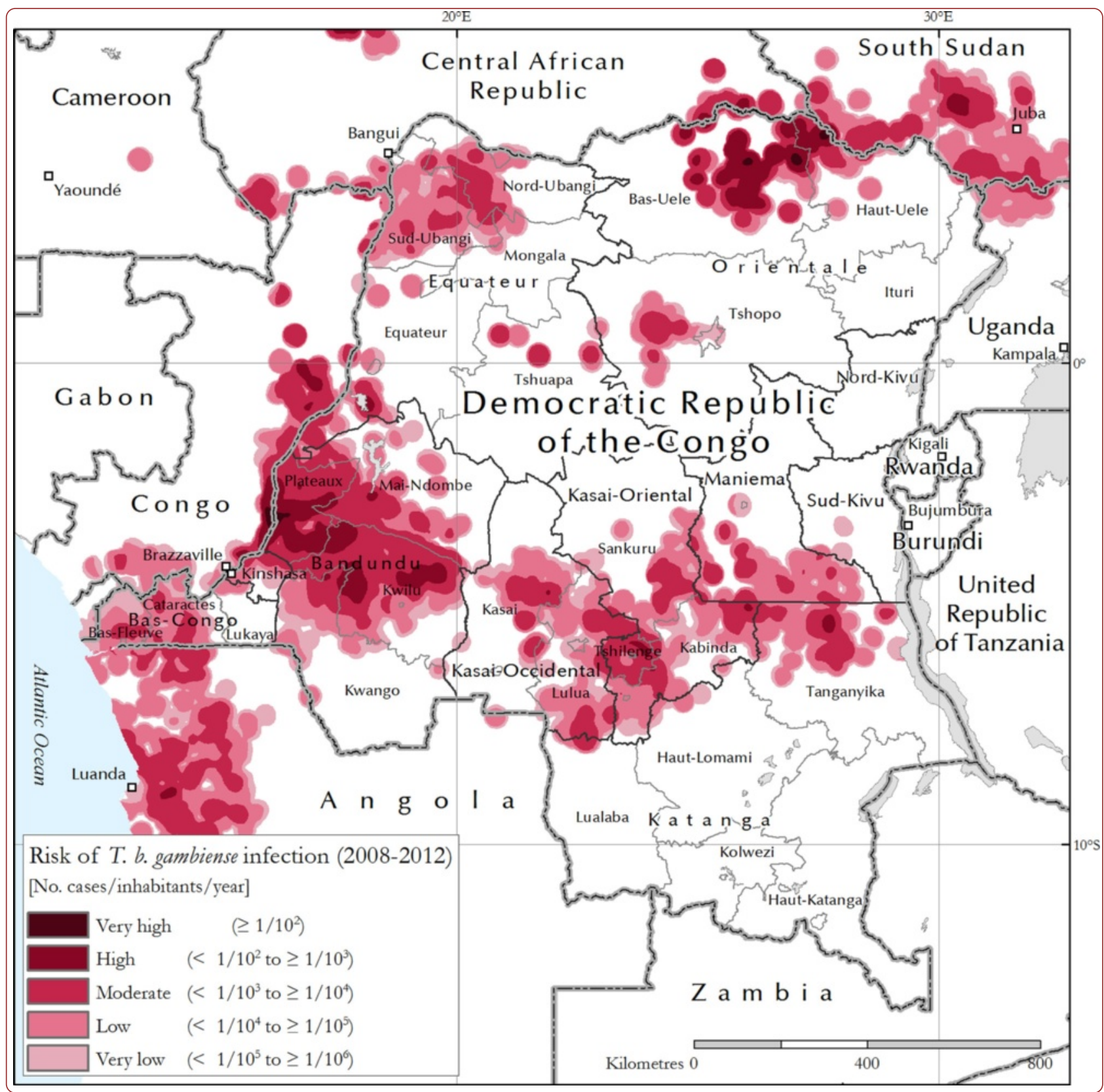

\title{
Human African trypanosomiasis in the Democratic Republic of the Congo: disease distribution and risk
}

Lumbala et al. 


\title{
Human African trypanosomiasis in the Democratic Republic of the Congo: disease distribution and risk
}

Crispin Lumbala ${ }^{1}$, Pere P. Simarro ${ }^{2}$, Giuliano Cecchi ${ }^{3}$, Massimo Paone $^{4}$, José R. Franco ${ }^{2 *}$, Victor Kande Betu Ku Mesu ${ }^{5}$, Jacquies Makabuza ${ }^{1}$, Abdoulaye Diarra ${ }^{6}$, Shampa Chansy ${ }^{1}$, Gerardo Priotto $^{2}$, Raffaele C. Mattioli ${ }^{4}$ and Jean G. Jannin ${ }^{2}$

\begin{abstract}
Background: For the past three decades, the Democratic Republic of the Congo (DRC) has been the country reporting the highest number of cases of human African trypanosomiasis (HAT). In 2012, DRC continued to bear the heaviest burden of gambiense HAT, accounting for $84 \%$ of all cases reported at the continental level (i.e., 5,968/7,106). This paper reviews the status of sleeping sickness in DRC between 2000 and 2012, with a focus on spatio-temporal patterns. Epidemiological trends at the national and provincial level are presented.

Results: The number of HAT cases reported yearly from DRC decreased by $65 \%$ from 2000 to 2012, i.e., from 16,951 to 5,968. At the provincial level a more complex picture emerges. Whilst HAT control in the Equateur province has had a spectacular impact on the number of cases ( $97 \%$ reduction), the disease has proved more difficult to tackle in other provinces, most notably in Bandundu and Kasai, where, despite substantial progress, HAT remains entrenched. HAT prevalence presents its highest values in the northern part of the Province Orientale, where a number of constraints hinder surveillance and control.

Significant coordinated efforts by the National Sleeping Sickness Control Programme and the World Health Organization in data collection, reporting, management and mapping, culminating in the Atlas of HAT, have enabled HAT distribution and risk in DRC to be known with more accuracy than ever before. Over 18,000 locations of epidemiological interest have been geo-referenced (average accuracy $\approx 1.7 \mathrm{~km}$ ), corresponding to $93.6 \%$ of reported cases (period 2000-2012). The population at risk of contracting sleeping sickness has been calculated for two five-year periods (2003-2007 and 2008-2012), resulting in estimates of 33 and 37 million people respectively.

Conclusions: The progressive decrease in HAT cases reported since 2000 in DRC is likely to reflect a real decline in disease incidence. If this result is to be sustained, and if further progress is to be made towards the goal of HAT elimination, the ongoing integration of HAT control and surveillance into the health system is to be closely monitored and evaluated, and active case-finding activities are to be maintained, especially in those areas where the risk of infection remains high and where resurgence could occur.
\end{abstract}

Keywords: Human African trypanosomiasis, HAT, Sleeping sickness, Trypanosoma brucei gambiense, Democratic Republic of the Congo, DRC

\footnotetext{
*Correspondence: francoj@who.int

${ }^{2}$ World Health Organization, Control of Neglected Tropical Diseases, Innovative and Intensified Disease Management, 1211, Geneva 27, Switzerland

Full list of author information is available at the end of the article
} 


\section{Background}

Human African trypanosomiasis (HAT), also known as sleeping sickness, is a tropical disease caused by protozoa of the Genus Trypanosoma, which are transmitted by the haematophagous tsetse flies (Genus: Glossina). Two forms of sleeping sickness are distinguished: one is found in western and central Africa, its causative agent is T. brucei gambiense and its progression is generally characterized by a long paucisymptomatic phase that can last several years; the other, caused by T. b. rhodesiense, is endemic to eastern and southern Africa and it is characterized by a much more rapid onset of overt symptoms, as well as a faster progression. Both forms almost invariably lead to death, unless appropriate treatment is provided.

In the Democratic Republic of the Congo (DRC), HAT is caused by T. b. gambiense, for which humans are the main reservoir. T. b. rhodesiense, which is characterized by a significant animal reservoir, is not reported from DRC, but it is present in neighbouring Tanzania, along the eastern shores of Lake Tanganyika [1].

The control of the gambiense form of HAT hinges mainly on mass screening of at-risk populations, passive detection and treatment of infected individuals. Targeted vector control can contribute to disease control, especially in areas of intense transmission, by reducing vector density and hence vector-human contact [2].

Despite the high level of control achieved in the sixties [3], for the past three decades DRC has been the country reporting the highest number of sleeping sickness cases $[2,4]$. In particular, following the sudden termination of the Belgian bilateral aid in 1990, and in a context of insecurity and general breakdown of the Congolese health system, the disease flared up [5], reaching alarming levels in the second half of the 1990s. At that point in time, over 25,000 new cases were being reported annually. The tide was only reversed when Belgian bilateral aid was resumed in 1998, and large scale screening activities and treatment programmes were restarted [6].

To date, DRC continues to bear the heaviest burden of gambiense HAT, having reported $84 \%$ of all African cases in 2012 (i.e., 5,968/7,106). Therefore, achieving the international goal of gambiense HAT elimination [7] will depend to a large extent on the progress that DRC will be able to make.

In this paper we review the status of sleeping sickness in DRC from 2000 to 2012, with a focus on spatiotemporal patterns. Epidemiological trends at the national and provincial level are provided. National and provincial maps of HAT distribution are presented, thus adding to previously published information on disease distribution in other HAT endemic countries [1,8]. Risk maps at the national and provincial levels are also presented for two five-year periods (2003-2007 and 2008-2012). Lastly, a range of control data are presented, which enable disease distribution and risk to be better understood and interpreted.

The study was conducted in the framework of the Atlas of HAT, an initiative of the World Health Organization (WHO), jointly implemented with the Food and Agriculture Organization of the United Nations (FAO), in the framework of the Programme Against African Trypanosomosis (PAAT) [1].

\section{Material and methods}

\section{Sources}

The main source of data for this study was the National Sleeping Sickness Control Programme-NSSCP (Programme National de Lutte contre la Trypanosomiase Humaine Africaine), which provided information on active screening activities conducted by mobile teams, as well as data on passive detection carried out by the Centres for Diagnosis, Treatment and Control (Centre de diagnostic, traitement et contrôle-CDTC) operated by the NSSCP and by health referral centres. The NSSCP structure in DRC presently includes a national coordination unit based in Kinshasa and eleven provincial/sub-provincial coordination units. Due to their size, the provinces of Bandundu and Equateur split provincial coordination into two subprovincial units (i.e., north and south). By contrast, the provinces of Katanga and Maniema are managed by the same coordination unit. Sankuru, a district of difficult access in the Kasai-Oriental province, is managed since 2011 by a separate coordination unit based in the town of Wembo Nyama.

Between 2000 and 2012, each provincial or subprovincial coordination unit operated between 1 and 13 specialized mobile teams, for an average total of 39 mobile teams/year for the whole country. At the end of 2012, 34 mobile teams were active in the following provinces/ sub-provinces (number of mobile teams in brackets): Bandundu nord (7), Bandundu sud (6), Bas-Congo (1), Equateur nord (5), Equateur sud (1), Kasai-Occidental (3), Kasai-Oriental (4), Katanga-Maniema (1-1), Kinshasa (1), Province Orientale (3, out of which 2 from Médecins Sans Frontières (MSF) acting in the North (Dingila and Ango) and 1 from PNLTHA based in Isangi, in the South) and Sankuru (1).

Additional data were provided by the Non-Governmental Organization (NGO) MSF. MSF's areas of intervention during the study period were located in the Equateur province and, most notably, in the Province Orientale, where for long periods insecurity has compounded remoteness in constraining the action of the NSSCP [9].

Two types of input data were used: (1) annual reports compiled by the national coordination unit, and containing province-level summaries for a range of HAT control and surveillance data, and (2) village-level data generated by the provincial and sub-provincial coordination units 
and NGOs. The former input files were used to investigate epidemiological trends at the national and provincial levels from 2000 to 2012, while the latter were the basis for building a geospatial database of HAT in DRC, and subsequent HAT mapping and risk assessment.

\section{Mapping the geographic distribution of HAT}

The distribution of HAT cases and HAT active screening activities in DRC was mapped using methods developed for the Atlas of HAT $[1,10]$. The presented distribution data cover the period 2000-2012, and they are based on the latest update of the Atlas of HAT (reference date: 6 March 2015).

The input data used to build the HAT geospatial database were typically represented by digital spreadsheets. The spreadsheets normally reported the monthly number of new HAT cases and of people screened, distinguishing between active and passive detection. The village name and the related administrative units were also present in the input data, including the Zone de Santé (Health Zone) and the Aire de Santé (Health Area), which constitute the two territorial subdivisions of the Congolese health system. The Zone de Santé covers between 100 and 150 thousand people, whereas the Aire de Santé normally covers an average of 10 thousand people in urban areas and 5 thousand people in rural areas. Information on the stage of the disease (i.e., the first-haemolymphatic, versus the second-meningoencephalitic) was only specified in the village-level input files provided by MSF (i.e., $4 \%$ of HAT cases). By contrast, stage information was fully provided at province-level in the NSSCP annual reports. In the case of active screening activities, the number of people living in the screened village (i.e., census) was normally reported in the village-level input datasets (approximately $72 \%$ of screening events).

In geo-referencing villages, the gold standard was the Global Positioning System (GPS), which is frequently used by the NSSCP. In addition to GPS, coordinates were also derived from a variety of sources, most notably from the GEOnet Names Server and other online gazetteers [1]. Qualitative information generated by NSSCP field staff also provided substantial input for geo-referencing.

To enable analysis in a Geographic Information System (GIS), input files were harmonized and imported in a geographic database, including all fields required for the continental Atlas of HAT (i.e., year, census, number of people screened, number of new HAT cases, surveillance type-either active or passive-parasite subspecies, disease stage-either first or second-country name, location name, location coordinates, mapping accuracy and sources).

In addition to the above standard fields for the Atlas of HAT, a few information items specific to DRC were also imported in the database, with a view to facilitating its utilization at the national level. For the geographical locations (e.g., villages), additional information included the names of all reported administrative units (i.e., province, district, territory, sector/collectivité, grouping, village and neighbourhood), as well as the names of the health system units (i.e., Zone de Santé and Aire de Santé). For data related to active screening activities, the name of the mobile team was also retained.

Although most HAT cases are reported from rural areas, a sizeable number of urban residents are also affected. This phenomenon is generally related to city dwellers who frequently visit neighbouring rural areas, as studied in some detail in the city of Kinshasa [11-15].

For all mapped HAT cases and geographic locations, mapping accuracy was estimated with methods already described [1].

\section{Risk mapping}

The broad patterns of HAT risk at the continental level have already been presented elsewhere $[8,16]$. The present paper is focused on the risk in DRC over two five-year study periods (2003-2007 and 2008-2012), and it also includes Province-level risk maps. Periods of 5 years have been identified as particularly interesting to monitor the elimination of gambiense HAT $[2,8]$.

The methodology used to estimate and map the risk of HAT has already been described [16, 17]. In essence, a risk function is estimated through kernel smoothing [18], which enables GIS point layers to be converted into continuous intensity surfaces. In this context, intensity is defined as the number of events per unit area [19]. Two smoothed surfaces are derived, one for HAT cases and one for human population. Landscan databases constitute the source of human population data [20,21]. The ratio of the two intensity surfaces defines the risk function ' $R$ '. Thresholds are applied to the risk function in order to distinguish different categories of risk, ranging from 'very high' to 'very low' (Table 1). Finally, Landscan population database is used to calculate the number of people at risk at the end of the study periods (2007 and 2012 respectively).

In addition to geo-referenced HAT cases, also the cases not yet mapped at the village-level were used in the risk analysis. The latter include 5,397 cases (i.e., $7 \%$ of the total reported in 2003-2012), and they were distributed among mapped locations by means of proportional allocation [17]. In particular, 2,579 cases (i.e., $48 \%$ of the total unmapped) were allocated by using information on the 'Aire de sante', whose radius rarely exceeds $6 \mathrm{~km}$. For 493 cases $(9 \%$ of the total unmapped), for which information on the corresponding 'Aire de sante' was unavailable, the 'Zone de Santé was used instead (average size $4,600 \mathrm{~km}^{2}$ ). The remaining 2,325 cases (i.e., $43 \%$ of the total unmapped) were allocated at coarser administrative levels. 
Table 1 Thresholds for the definition of sleeping sickness risk categories. Thresholds are applied to the risk function R (i.e., the ratio between the average annual intensity of HAT cases and the intensity of exposed population). Where the risk function is $<10^{6}$ (i.e., $<1$ HAT case per $10^{6}$ people per annum), risk is considered 'marginal' [17]

\begin{tabular}{llc}
\hline Category of risk & $\mathrm{R}$ & HAT cases per annum \\
\hline $\begin{array}{l}\text { Very high } \\
\text { High }\end{array}$ & $10^{3}<\mathrm{R}<10^{2}$ & 1 per $10^{2}$ people \\
Moderate & 11 per $10^{3}$ people AND & people \\
Low & $10^{4}<R<10^{3}$ & 1 per $10^{4}$ people AND \\
& $10^{5}<R<10^{4}$ & 1 per $10^{3}$ people \\
Very low & $10^{5}$ people AND \\
& $10^{6}<R<10^{5}$ & 1 per $10^{4}$ people \\
& & $<1$ per $10^{6}$ people AND $10^{5}$ people \\
\hline
\end{tabular}

\section{Results}

Epidemiological trends, 2000-2012

\section{National level}

The number of new HAT cases reported yearly from DRC decreased by $65 \%$ from 2000 to 2012, i.e., from 16,951 to 5,968 . The slight increase observed between 2011 and 2012 is to be ascribed to intensive active case detection in the Bandundu province aimed at the enrolment of HAT patients in clinical trials.

In the same period a similar decrease was observed in cases detected by both passive (73.3 \%) and active screening $(56.7 \%)$, as shown in Table 2. Interestingly, infection rate (i.e., cases detected/people screened) in active screening decreased by $58 \%$ during the first four years of the study period, but it remained fairly stable thereafter. Infection rate in passive screening decreased by $82.3 \%$ between 2000 and 2008, while stagnation has been observed during the last six years of the study period.

As concerns the intensity of surveillance, from 2005 a decrease was observed in the number of people actively screened, only partly offset by a sustained increase in people passively screened.

In active screening activities the disease stage ratio (i.e., the ratio between the number of cases detected in second stage and those detected in first stage) has decreased by 37.3 \% (from 0.67 in 2000 to 0.42 in 2012). As expected, higher stage ratios characterized passive detection throughout the whole study period. However, in relative terms, a similar decrease was observed (46.9\%), with a minimum of 1.33 in 2011.

The ratio between passively to actively detected cases has hovered around one throughout the study period, except for 2001, 2009 and 2012 when it was $0.68 \%$, $0.67 \%$ and $0.59 \%$ respectively (Table 2 ). Average attendance rates in active screening activities remained fairly high and stable throughout the study period, with an average of $78.6 \%$ (Table 3 ).

\section{Provincial level}

As shown in Fig. 1, national averages presented in Table 2 hide substantial variation at the provincial level. Table 4 shows the number of new HAT cases reported between 2000 and 2012 by the different Provinces, while Additional file 1 presents attendance rates during active screening activities-which ranged from $73.1 \%$ in Kasai to $86.6 \%$ in Province Orientale. More detailed data on HAT control and surveillance in the different provinces of DRC are provided in Additional file 2. From these data, the main provincial trends can be deduced.

Bandundu Province, which covers an area of 296,500 km² (12.6\% of DRC), accounts for the largest share of cases reported since 2001 (i.e., $\approx 47.6 \%$ ). The Province was divided in 2004 into two sub-provincial coordination units, i.e., Bandundu Nord, located in the city of Bandundu, and Bandundu Sud, located in the city of Kikwit. Bandundu has been the recipient of almost half of the budget for HAT control in DRC during the last ten years (NSSCP, unpublished). This commitment enabled to maintain a substantial and sustained effort in terms of active case finding, including what the NSSCP calls "action d'envergure", in which several mobile teams focus on a highly endemic "zone de santé". On average, more than 800,000 people were screened in Bandundu every year. On the other hand, in 2009 the province initiated the process of integrating HAT control and surveillance in the health system.

Data on passive screening in Bandundu differ from the national trends. Whereas the decrease in cases detected by passive screening experienced at national level has been of $73.3 \%$, in Bandundu it has been of $53.7 \%$. If measured in terms of the number of cases detected, the epidemiological situation in Bandundu improved over the study period, with a reduction of $43 \%$; however, this reduction was below the national average (65\%).

Bas-Congo is relatively small a province (i.e., $54,400 \mathrm{~km}^{2}$ ), which also benefits from a good transport network. This facilitates HAT control activities. In addition, proximity to NSSCP headquarters in Kinshasa makes logistical support to the provincial coordination unit easier. The decline in number of cases, which at $87 \%$ was sharper than the $65 \%$ national average, can largely be ascribed to these comparative advantages. In 2009 the improvements in the epidemiological situation led to initiate the process of integration of HAT into the health system, with the subsequent reduction in the number of mobile teams (from five at the beginning of the study period to one in 2011). The mobile team presently operational plays a role that is largely reactive, visiting areas where passive detection shows an increase in the number of detected cases.

Equateur is a vast province of $395,700 \mathrm{~km}^{2}$ that was split into two sub-provincial coordination units-Equateur Nord 
Table 2 HAT control and surveillance in DRC (2000-2012)

\begin{tabular}{|c|c|c|c|c|c|c|c|c|c|c|c|c|c|c|c|c|}
\hline \multirow[t]{3}{*}{ Year } & \multicolumn{7}{|c|}{ Active screening } & \multicolumn{7}{|c|}{ Passive surveillance } & \multicolumn{2}{|l|}{ Total } \\
\hline & \multirow{2}{*}{$\begin{array}{l}\text { People } \\
\text { screened }\end{array}$} & \multirow{2}{*}{$\begin{array}{l}\text { HAT } \\
\text { Cases }\end{array}$} & \multirow{2}{*}{$\begin{array}{l}\text { Infection } \\
\text { rate } \\
\qquad \%]\end{array}$} & \multicolumn{4}{|l|}{ Stage } & \multirow{2}{*}{$\begin{array}{l}\text { People } \\
\text { screened }\end{array}$} & \multirow{2}{*}{$\begin{array}{l}\text { HAT } \\
\text { Cases }\end{array}$} & \multirow{2}{*}{$\begin{array}{l}\text { Infection } \\
\text { rate } \\
\text { [\%] }\end{array}$} & \multicolumn{4}{|l|}{ Stage } & \multirow{2}{*}{$\begin{array}{l}\text { HAT } \\
\text { Cases }\end{array}$} & \multirow{2}{*}{$\begin{array}{l}\text { Passive } \\
\text { cases/ } \\
\text { active } \\
\text { cases }\end{array}$} \\
\hline & & & & P1 & P2 & N. $a^{a}$ & $\mathrm{P} 2 / \mathrm{P} 1$ & & & & P1 & P2 & N. $a^{a}$ & $\mathrm{P} 2 / \mathrm{P} 1$ & & \\
\hline 2000 & $1,442,951$ & 8,679 & 0.60 & 4,958 & 3,337 & 384 & 0.67 & 162,855 & 8,272 & 5.08 & 1,663 & 6,449 & 160 & 3.88 & 16,951 & 0.95 \\
\hline 2001 & $1,936,755$ & 10,286 & 0.53 & 6,013 & 3,379 & 894 & 0.56 & 91,483 & 7,014 & 7.67 & 1,269 & 5,507 & 238 & 4.34 & 17,300 & 0.68 \\
\hline 2002 & $1,925,443$ & 7,298 & 0.38 & 4,328 & 2,638 & 332 & 0.61 & 114,911 & 6,518 & 5.67 & 1,308 & 5,206 & 4 & 3.98 & 13,816 & 0.89 \\
\hline 2003 & $2,288,071$ & 5,781 & 0.25 & 3,359 & 2,234 & 188 & 0.67 & 117,887 & 5,678 & 4.82 & 980 & 4,679 & 19 & 4.77 & 11,459 & 0.98 \\
\hline 2004 & $2,360,962$ & 5,226 & 0.22 & 3,173 & 1,935 & 118 & 0.61 & 163,694 & 5,113 & 3.12 & 844 & 4,259 & 10 & 5.05 & 10,339 & 0.98 \\
\hline 2005 & $2,310,722$ & 4,919 & 0.21 & 3,189 & 1,590 & 140 & 0.50 & 151,497 & 5,330 & 3.52 & 1,031 & 4,246 & 53 & 4.12 & 10,249 & 1.08 \\
\hline 2006 & $2,227,855$ & 3,749 & 0.17 & 2,471 & 1,141 & 137 & 0.46 & 214,396 & 4,264 & 1.99 & 879 & 3,373 & 12 & 3.84 & 8,013 & 1.14 \\
\hline 2007 & $1,984,643$ & 4,142 & 0.21 & 2,810 & 1,218 & 114 & 0.43 & 217,561 & 4,013 & 1.84 & 911 & 3,074 & 28 & 3.37 & 8,155 & 0.97 \\
\hline 2008 & $1,452,082$ & 3,692 & 0.25 & 2,539 & 1,102 & 51 & 0.43 & 573,972 & 3,626 & 0.63 & 945 & 2,666 & 15 & 2.82 & 7,318 & 0.98 \\
\hline 2009 & $1,876,160$ & 4,290 & 0.23 & 3,316 & 847 & 127 & 0.26 & 183,554 & 2,888 & 1.57 & 706 & 2,149 & 33 & 3.04 & 7,178 & 0.67 \\
\hline 2010 & $1,740,534$ & 2,802 & 0.16 & 2,016 & 734 & 52 & 0.36 & 278,606 & 2,822 & 1.01 & 849 & 1,966 & 7 & 2.32 & 5,624 & 1.01 \\
\hline 2011 & $1,189,603$ & 2,652 & 0.22 & 2,073 & 538 & 41 & 0.26 & 234,632 & 2,938 & 1.25 & 1,256 & 1,669 & 13 & 1.33 & 5,590 & 1.11 \\
\hline 2012 & $1,497,047$ & 3,759 & 0.25 & 2,592 & 1,099 & 68 & 0.42 & 237,319 & 2,209 & 0.93 & 719 & 1,480 & 10 & 2.06 & 5,968 & 0.59 \\
\hline Total & $24,232,828$ & 67,275 & 0.28 & 42,837 & 21,792 & 2,646 & 0.51 & $2,742,367$ & 60,685 & 2.21 & 13,360 & 46,723 & 602 & 3.50 & 127,960 & 0.90 \\
\hline Average & $1,864,064$ & 5,175 & 0.28 & 3,295 & 1,676 & 204 & 0.48 & 210,951 & 4,668 & 3.01 & 1,028 & 3,594 & 46 & 3.45 & 9,843 & 0.93 \\
\hline
\end{tabular}

${ }^{\mathrm{a} N . a .}=$ Not available

based in Bwamanda and Equateur Sud based in Mbandaka. The disease is mainly prevalent in the northern part of the province.

The southern part is characterized by low human population density as well as by numerous rivers and

Table 3 Attendance rate in HAT active screening activities in DRC (2000-2012) ${ }^{a}$

\begin{tabular}{|c|c|c|c|}
\hline Year & Mobile teams [number] & $\begin{array}{l}\text { Census (in actively- } \\
\text { screened locations) }\end{array}$ & $\begin{array}{l}\text { Attendance } \\
\text { rate }[\%]\end{array}$ \\
\hline 2000 & 33 & $1,981,804$ & 72.81 \\
\hline 2001 & 33 & $2,493,959$ & 77.66 \\
\hline 2002 & 43 & $2,553,761$ & 75.40 \\
\hline 2003 & 46 & $2,780,623$ & 82.29 \\
\hline 2004 & 47 & $2,795,687$ & 84.45 \\
\hline 2005 & 45 & $2,806,751$ & 82.33 \\
\hline 2006 & 45 & $2,785,726$ & 79.97 \\
\hline 2007 & 38 & $2,347,330$ & 84.55 \\
\hline 2008 & 34 & $2,329,327$ & 62.34 \\
\hline 2009 & 33 & $2,413,026$ & 77.75 \\
\hline 2010 & 35 & $2,350,939$ & 74.04 \\
\hline 2011 & 34 & $1,367,989$ & 86.96 \\
\hline 2012 & 34 & $1,820,520$ & 82.23 \\
\hline Average & 38 & $2,371,342$ & 78.67 \\
\hline
\end{tabular}

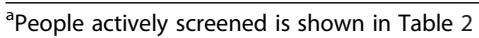

${ }^{\mathrm{b}}$ Collected by mobile teams dense vegetation hindering access. Large areas in Equateur Sud are beyond the reach of NSSCP teams, and some communities are extremely isolated (e.g., pygmies). Nevertheless, in this context, targeted HAT surveys have not shown worrying results. Cases reported from Equateur Sud account for only $7 \%$ of the total cases reported at the provincial level. Subsequently, trends in Equateur province are to a large extent those observed in the northern part.

In Equateur Nord, a spectacular reduction in the number of reported cases has been observed over the study period. In 2000, Equateur was the major contributor to the total HAT cases reported in DRC (i.e., $40.2 \%$ ), whereas in 2012 its share plummeted to $3.3 \%$, corresponding to a reduction of $97 \%$ in reported cases. These results were achieved in spite of remoteness, and they were made possible by the important support of financial partners, as well as the commitment of staff, the judicious management and the effective partnership between the NSSCP and the NGO (Memisa) in charge of implementation. The Equateur province has initiated the process of integration of HAT control and surveillance into the health system. In recent years, despite the majority of CDTC having been closed, most reported cases were detected by passive screening and a subsequent increase in the proportion of second versus first stage cases was observed. Very close monitoring of the performance of the health system is imperative in this 


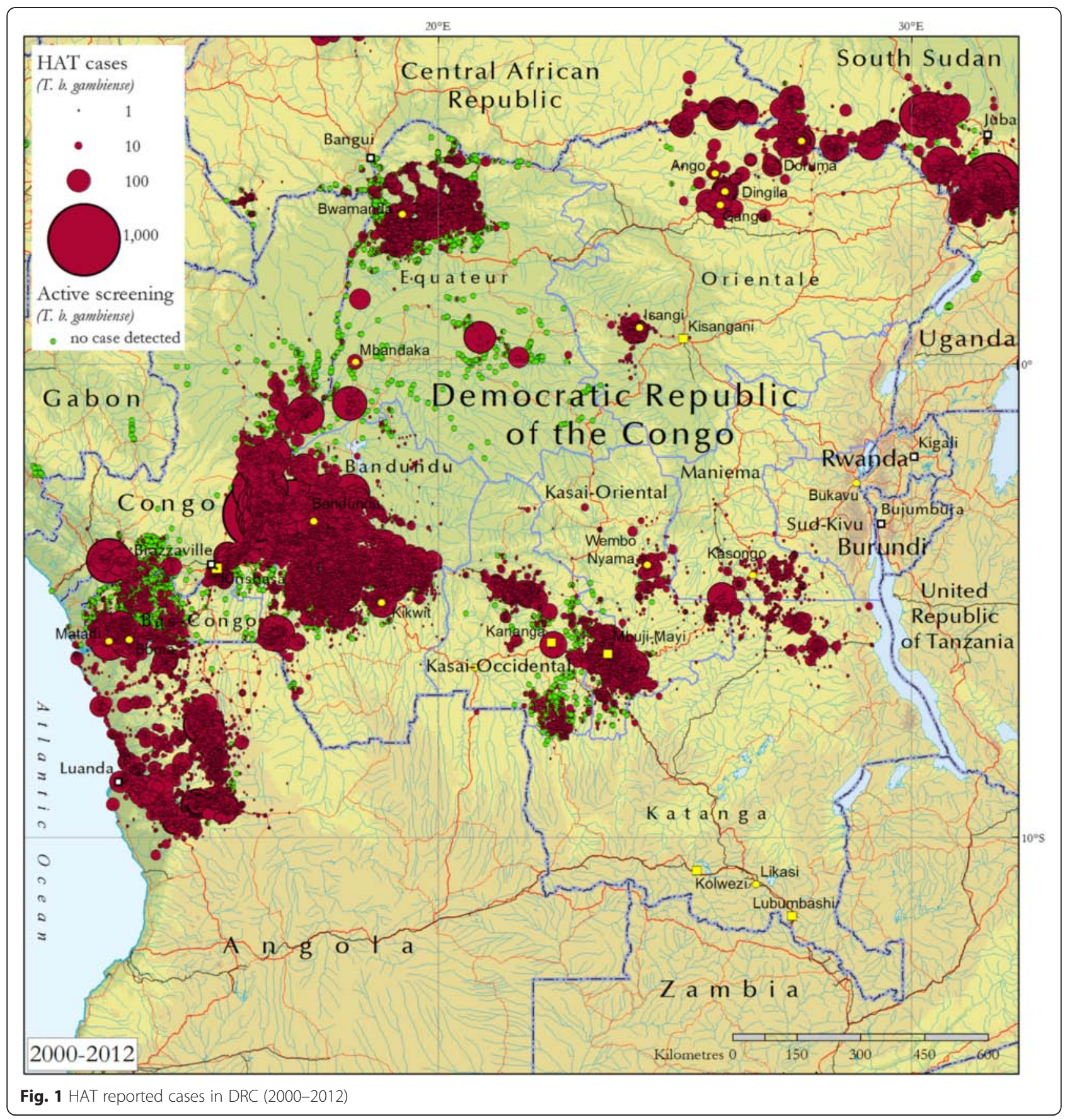

province, especially because attendance rate in active screenings has fallen below $50 \%$. The rate of utilization of fixed health facilities also needs to be monitored.

Kasai-Oriental and Kasai-Occidental were managed by a single provincial coordination unit until 2005, when coordination was split between Mbuji-Mayi (for KasaiOriental) and Kananga (for Kasai-Occidental). Access to HAT foci is generally difficult because of the poor conditions of the road network. Access is especially problematic in Kasai-Occidental because of the distance between
Kananga and the HAT foci. By contrast, the foci in KasaiOriental are located around Mbuji-Mayi, which simplifies the activities of the mobile teams. In addition, the epidemiological significance of these two provinces - which, when combined, represent the second contributor to HAT cases in DRC after Bandundu - brought about a number of operational research projects. These contributed to upgrading logistics, heath care facilities and human resources, and thus boosted control activities. At the same time, intense traditional mining of diamonds continues to 
Table 4 T. b. gambiense Sleeping Sickness in the Provinces of DRC: new cases reported between 2000 and 2012

\begin{tabular}{|c|c|c|c|c|c|c|c|c|c|c|c|c|c|c|c|}
\hline Province & & 2000 & 2001 & 2002 & 2003 & 2004 & 2005 & 2006 & 2007 & 2008 & 2009 & 2010 & 2011 & 2012 & Total \\
\hline \multirow{3}{*}{$\begin{array}{l}\text { Bandundu } \\
\text { (Nord and Sud) }\end{array}$} & & 5,586 & 7,179 & 6,261 & 5,367 & 4,604 & 4,812 & 3,986 & 3,826 & 3,916 & 4,456 & 2,923 & 2,502 & 3,167 & 58,585 \\
\hline & Bandundu Nord & 3,138 & 3,989 & 3,630 & 2,568 & 2,540 & 2,746 & 1,926 & 1,677 & 2,044 & 2,061 & 1,409 & 1,433 & 2,047 & 31,208 \\
\hline & Bandundu Sud & 2,448 & 3,190 & 2,631 & 2,799 & 2,064 & 2,066 & 2,060 & 2,149 & 1,872 & 2,395 & 1,514 & 1,069 & 1,120 & 27,377 \\
\hline Bas-Congo & & 792 & 719 & 739 & 517 & 266 & 201 & 172 & 110 & 196 & 195 & 164 & 104 & 106 & 4,281 \\
\hline \multirow{3}{*}{$\begin{array}{l}\text { Equateur } \\
\text { (Nord and Sud) }\end{array}$} & & 6,812 & 5,096 & 2,594 & 1,700 & 1,320 & 902 & 691 & 657 & 552 & 425 & 308 & 321 & 197 & 21,575 \\
\hline & Equateur Nord & 6,673 & 4,990 & 2,436 & 1,597 & 1,250 & 824 & 572 & 532 & 418 & 270 & 184 & 219 & 107 & 20,072 \\
\hline & Equateur Sud & 139 & 106 & 158 & 103 & 70 & 78 & 119 & 125 & 134 & 155 & 124 & 102 & 90 & 1,503 \\
\hline \multirow{3}{*}{$\begin{array}{l}\text { Kasaï (Occidental } \\
\text { and Oriental) }\end{array}$} & & 2,811 & 2,905 & 3,173 & 2,606 & 2,720 & 2,766 & 2,115 & 1,896 & 1,431 & 1,376 & 967 & 1,054 & 872 & 26,692 \\
\hline & Kasaï-Occidental & - & - & - & - & - & 618 & 515 & 575 & 357 & 386 & 270 & 356 & 171 & - \\
\hline & Kasaï-Oriental & - & - & - & - & - & 2,148 & 1,600 & 1,321 & 1,074 & 990 & 697 & 698 & 701 & - \\
\hline \multirow{3}{*}{$\begin{array}{l}\text { Katanga and } \\
\text { Maniema }\end{array}$} & & 323 & 709 & 589 & 728 & 667 & 391 & 355 & 368 & 218 & 137 & 122 & 115 & 218 & 4,940 \\
\hline & Katanga & - & - & - & - & - & 108 & 80 & 99 & 0 & 66 & 52 & 62 & 91 & - \\
\hline & Maniema & 323 & - & - & - & - & 283 & 275 & 269 & 218 & 71 & 70 & 53 & 127 & - \\
\hline Kinshasa & & 627 & 685 & 459 & 286 & 331 & 256 & 228 & 399 & 238 & 198 & 153 & 143 & 134 & 4,137 \\
\hline Province Orientale & & 0 & 5 & 0 & 251 & 431 & 920 & 463 & 897 & 767 & 391 & 986 & 1,351 & 1,273 & 7,735 \\
\hline Sud-Kivu & & 0 & 2 & 1 & 4 & 0 & 1 & 3 & 2 & 0 & 0 & 1 & 0 & 1 & 15 \\
\hline Total & & 16,951 & 17,300 & 13,816 & 11,459 & 10,339 & 10,249 & 8,013 & 8,155 & 7,318 & 7,178 & 5,624 & 5,590 & 5,968 & 127,960 \\
\hline
\end{tabular}

facilitate disease transmission, whilst also limiting participation in active screening surveys. Recently, a decrease in the trade of diamonds has caused some people to quit mining in riverine, forested environments, and to return to their villages of origin for farming. This may pose an increased risk of transmission in some silent areas, and monitoring of the performance of the active and passive detection system is therefore needed.

Access from Mbuji-Mayi is only difficult to the northern part of Kasai-Oriental (i.e., Sankuru), which in the past was managed by the provincial coordination in Maniema. In 2011, this region has been established as a new subprovincial coordination unit, with its base in the city of Wembo Nyama. For the purpose of this study, data from Sankuru were still included in those from Kasai Oriental.

Kasai is the only province where the number of people screened by mobile teams more than doubled over the study period, while the trend in reported cases is in line with the national average (i.e., $69 \%$ reduction).

Katanga and Maniema share a border as well as transboundary HAT foci. This proximity and the relatively low number of cases reported enable a single provincial coordination unit based in Kasongo (Maniema) to manage both Provinces. All foci are surveyed by two mobile teams, one for each Province. Logistics is difficult because of the large distance from NSSCP headquarters in Kinshasa and for the very poor conditions of the roads. Insecurity also constrains access to transmission areas, which contributes to confounding the epidemiological picture in these provinces. Knowledge gaps notwithstanding, the generally low endemicity, combined with a $32 \%$ reduction in HAT reported cases, led to initiate the process of integration of HAT control and surveillance into the health system. This allowed to shift mobile teams to Sankuru. In this context, close monitoring and evaluation of the health system performance in detecting HAT cases is warranted. As already observed for Equateur province, most of the cases from Katanga and Maniema are detected by passive detection, with an increase in the disease stage ratio in recent years.

During the study period the provincial coordination unit in Kasongo (Maniema) has reported a few (six) cases originating from Sud Kivu. Nevertheless, there is reason to believe that these individuals, although administratively associated to Sud Kivu, are likely to have been infected in the transmission areas in Maniema, where they conduct their main activities (V. Kande personal communication).

Kinshasa Province includes the urban and the rural Kinshasa for a total area of $10,500 \mathrm{~km}^{2}$. A provincial coordination is based in the city of Kinshasa. The rural Kinshasa covers mainly the north-eastern area of the province (i.e., the communes of Maluku and Nsele). Although under the administrative umbrella of Kinshasa, farming is the main activity and the setting is the same we can observe in other rural areas of DRC. As concerns 
urban Kinshasa, favourable ecosystems where transmission can occur do exist (e.g., along the many rivers that cross the city). Moreover, many residents of Kinshasa have strong commercial and recreational connections with HAT transmission areas, especially in neighbouring Bandundu province.

In Kinshasa province as a whole, improvements in the epidemiological situation were observed during the study period, with a $79 \%$ reduction in the number of cases. However, case detection largely relies on passive detection, and most cases continue to be detected in stage 2 .

The Province Orientale is a vast area of $502,900 \mathrm{~km}^{2}$. It is affected by serious security issues, mainly in its northern part, weak transportation infrastructure, and remoteness from NSSCP headquarters in Kinshasa. The provincial coordination unit is based in Isangi, and its location only enables it to cover transmission areas in the southern part of the province. Epidemiological trends are particularly difficult to interpret because of the above mentioned constraints to HAT control and surveillance activities [9]. Orientale is therefore the province where knowledge of the epidemiological situation is the least complete. Only the more accessible, southern part of the province has benefited from sustained HAT control since 2004. Data for the period 2000-2002 are particularly scanty, whilst infection rates found in following years indicate that transmission was very intense in some areas. Despite gaps in the epidemiological record, it is clear that this region has shown the highest HAT prevalence in the last years in the whole of DRC, especially in a few Zones de Santé located in the northern part of the province (e.g., Ganga-Dingila, Ango and Doruma). Between 2007 and 2014, MSF established a project implementing a control programme. Despite initial stumbling blocks caused by insecurity, the project managed to sustain its activities and the knowledge of HAT epidemiology in the province-as well as disease control-improved.

\section{The geographic distribution of HAT, 2000-2012}

As we write, 119,634 HAT cases (93.6\% of the total reported in the period 2000-2012) and 18,072 locations (86.8 \% of the total reported) have been mapped in DRC (Fig. 1) (Atlas of HAT reference date: 6 March 2015). The estimated average mapping accuracy is $900 \mathrm{~m}$ and $1,700 \mathrm{~m}$ for reported HAT cases and reported geographic locations respectively. The results of mapping at the regional level and the details on the geographical accuracy of mapped villages are summarized in Additional file 3. Provincial maps of HAT distribution for the period 2000-2012 are provided in Additional file 4. Furthermore, Additional file 5 provides separate maps for the periods 2003-2007 and 2008-2012 (both at the national and provincial level).

\section{The risk of HAT, 2003-2007 and 2008-2012}

The results of the risk analysis are mapped in Fig. 2 and summarized in Figs. 3 and 4. Additional file 6 provides province level details for areas and populations at risk, and the related province level maps are available from Additional file 7.

Taking the latest study period as a reference (i.e., 2008-2012), less than one third of the land area in DRC (i.e., 715 thousand $\mathrm{km}^{2}$ ) and approximately half of the population (i.e., 36.6 million) are estimated to be at various levels of HAT risk.

Areas at 'very high' to 'high' risk account for a relatively small proportion, i.e., $\approx 8 \%$ of the total at-risk area (down from $12 \%$ in $2003-2007$ ), and $\approx 4 \%$ of the total at-risk population (down from $8 \%$ in 2003-2007). As shown in the country-level risk map in Fig. $2 \mathrm{~b}$ and in the provincelevel risk maps (Additional file 7), these high risk areas are found mainly in Bandundu (Zones de Santé Kwamouth, Bolobo, Mushie, Bandundu, Nioki, Bokoro, Bagata, Kikongo, Kenge, Yasa Bonga, Masi Manimba, Mosango, Bulungu, Kimptutu, Ipamu, and Lusanga), Equateur (Zones de Santé Bikoro, Ntondo and Iboko), and Province Orientale (Zones de Santé Ganga-Dingila, Doruma, Ango, Bili and Poko). With the exception of Bas-Congo, Maniema and Sud and Nord Kivu, high risk areas are also present in all other provinces, including Kasai-Oriental (Zones de Santé Bibanga, Lubao, Tshitshimbi, and Kabinda) and Kasai-Occidental (Zones de Santé Kakenge), Katanga (Zones de Santé Nyunzu and Mbulula) and Kinshasa (Zones de Santé Maluku I).

Risk is estimated to be 'moderate' in sizable areas of Bandundu, Equateur and a number of other Provinces, accounting for $\approx 31 \%$ of the total at-risk area (down from $38 \%$ in 2003-2007), and $\approx 23 \%$ of the at-risk population (down from $32 \%$ in 2003-2007).

Although the total population at risk has increased by $10 \%$ between the two study periods, mainly due to population growth, the intensity of HAT risk has decreased. In particular, the population at high and very high risk has decreased by $45 \%$-from 2.8 to 1.5 million. The population at moderate risk also decreased from 10.5 to 8.2 million (i.e., $21 \%$ reduction). This national trend is not followed by Province Orientale, where the improvement in security conditions during the period 2008-2012 allowed access to pockets of previously unsurveyed populations. This resulted in an increase of $86 \%$ in the population at very high, high and moderate risk.

\section{Discussion}

Despite the fluctuations in intensity and variations in effectiveness of HAT control and surveillance activities, the number of new HAT cases reported from DRC to WHO has decreased almost every year in the period 2000-2012, with a total reduction of $65 \%$ 


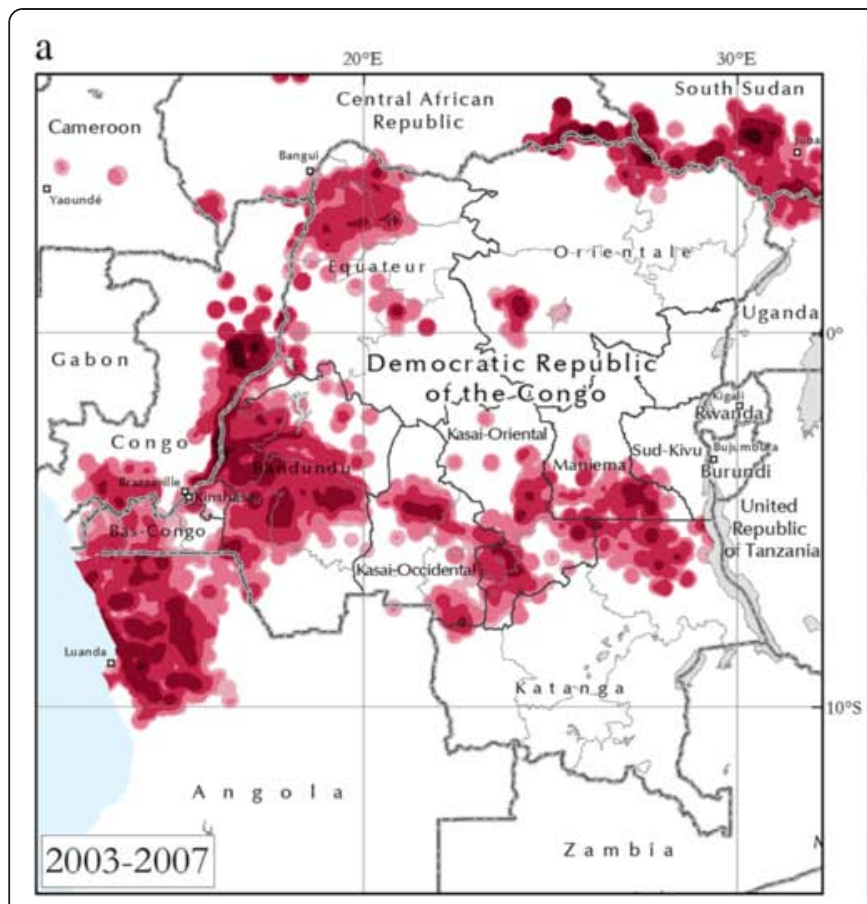

Risk of T. b. gambiense infection [No. cases/inhabitants/year]

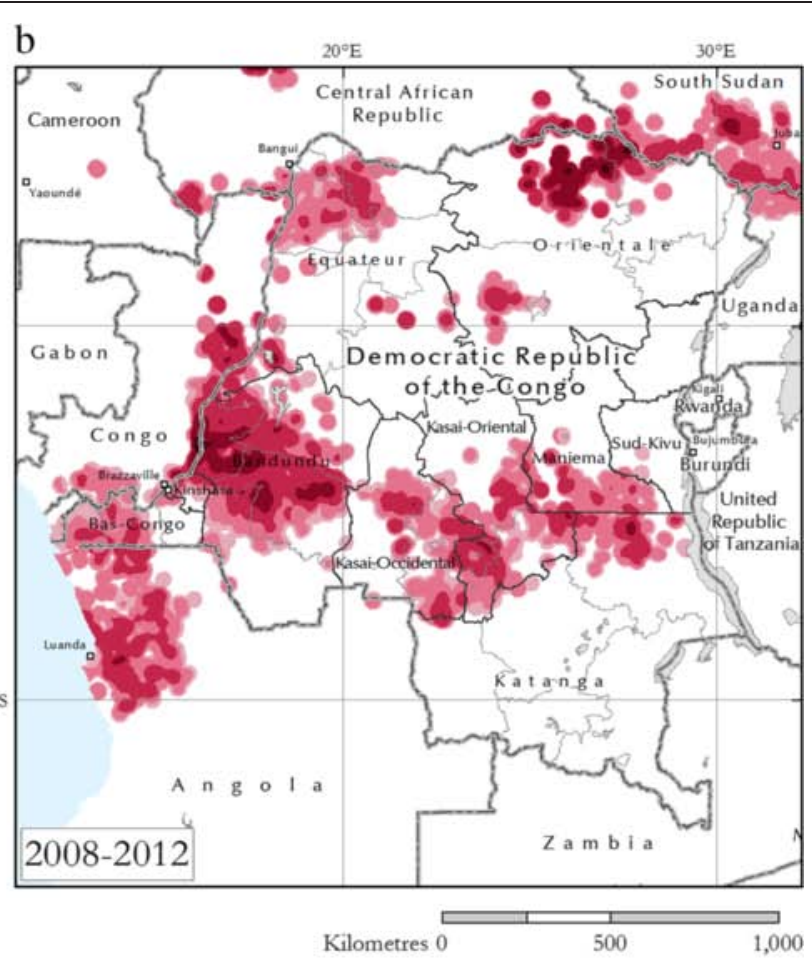

$\begin{array}{ll}\text { Low } & \left(<1 / 10^{4} \text { to } \geq 1 / 10^{5}\right) \\ \text { Very low } & \left(<1 / 10^{5} \text { to } \geq 1 / 10^{9}\right)\end{array}$

Fig. 2 The risk of T. b. gambiense infection in DRC, a 2003-2007 and b 2008-2012

(from 16,951 to 5,968). Although the downward national trend of reported cases is considered extremely positive, it is challenging to discuss national-level data for such a vast country as DRC. In depth analyses at the provincial and sub-provincial levels, beyond the scope of the present paper, would be needed.
The average attendance rate during active case-finding surveys, based on census data collected by mobile teams, has been stable around $79 \%$. Although mobile teams can not cover all areas of disease transmission, this figure indicates that they are at least in a position to detect most of the HAT infections occurring in their area of action. This attendance rate is in line with estimates
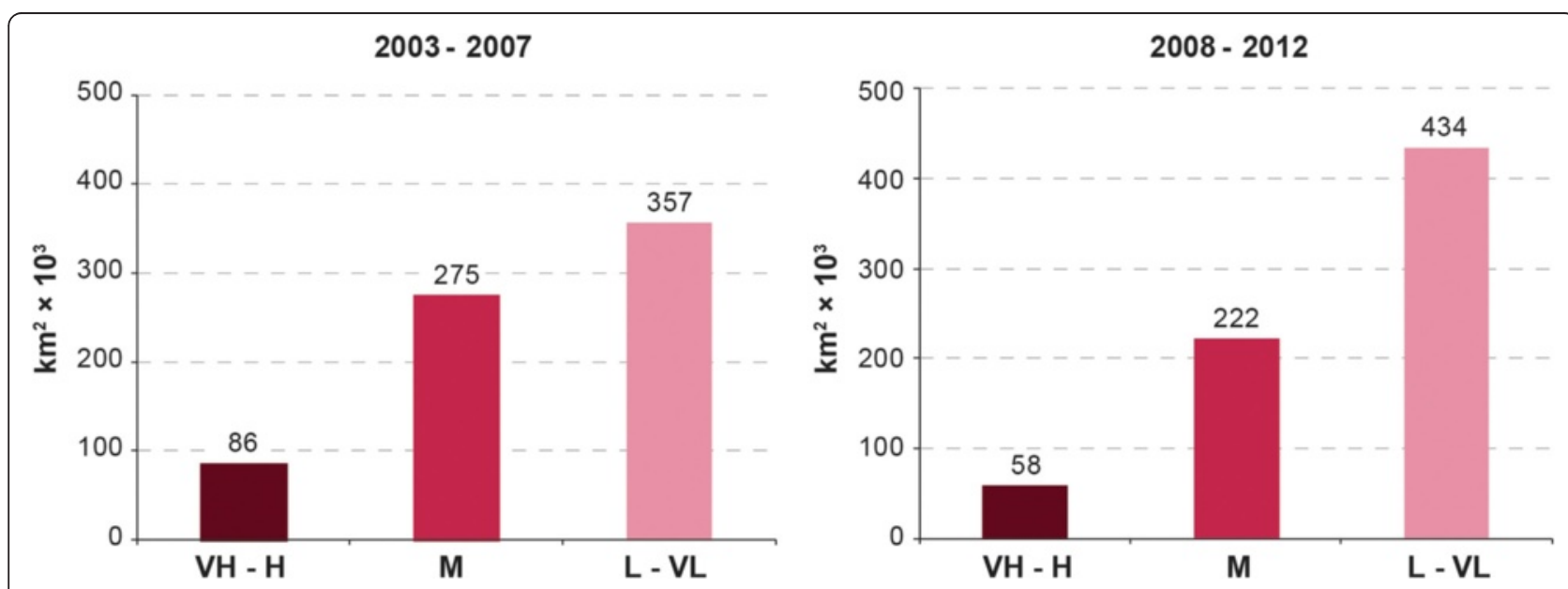

Fig. 3 The areas at risk of T. b. gambiense infection in DRC $\left(\mathrm{km}^{2} \times 10^{3}\right)$. Periods 2003-2007 and 2008-2012. VH: Very High; H: High; M: Moderate; L: Low and VL: Very Low 


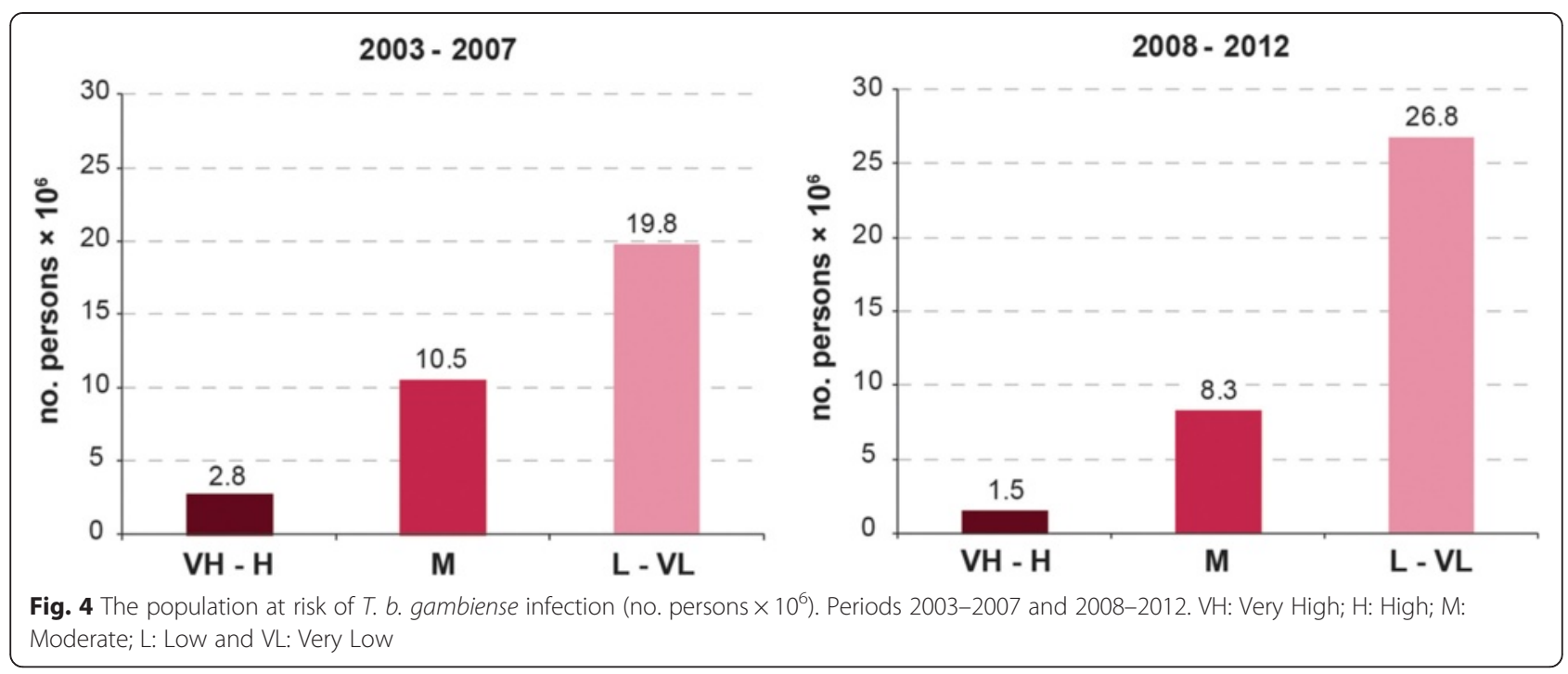

for the period 1997-1998 [22]. On the other hand, the ratio between passively versus actively detected cases has remained stable at around one. This can be related to one negative aspect (i.e., inability of active case-finding surveys to cover all transmission areas), but also to a positive one (i.e., capacity of passive surveillance to detect cases that escape active screening). Also, looking at the generally decreasing trend in the stage ratio (i.e., P2/P1), it appears that the capacity to detect cases in the early stage has improved. Concerning cases passively detected, it was unfortunately not possible to differentiate between cases detected by specialized NSSCP units like CDTC and those detected by recently involved health care facilities. However, detected passive cases indicate that disease transmission is still on-going in certain areas, which deserves an accurate identification and a quick and targeted reaction by mobile teams.

Despite the encouraging national trends summarized above, other observations give reason for concern. First, the intensity of active case-finding surveys is decreasing. Second, the NSSCP had a specialized network of centres for diagnosis and treatment (CDTC), staffed with motivated and skilled professionals; however, the progressive shift of responsibility for passive screening to the health system, while expanding HAT surveillance to more health care facilities, could diminish performance if staff are less motivated and skilled. Last, because of difficult geographical accessibility, security constraints and lack of funds, there still exist transmission areas not covered by adequate control and surveillance activities.

As a result of decreasing disease trends, the integration of HAT control and surveillance into the Health System has been for many years the objective of the NSSCP, and it has more recently found backing in the 'National strategy for the reinforcement of the health system'. The process of integration has been gradually rolled out in most endemic provinces, (except in the insecurity-ridden Province Orientale), either to replace mobile teams in areas where, due to low prevalence, they were neither effective nor sustainable, or to complement active screening in areas where the disease transmission is still high. Since 2009, the reduction of mobile teams and the integration of HAT control and surveillance into selected health care facilities have been mainly implemented in the provinces of Bandundu, Bas-Congo, Maniema, Katanga and Equateur Nord. These provinces have maintained one operational mobile team-except Bandundu (13 mobile teams) and Equateur Nord (five mobile teams) - to act and react in areas of active transmission. The members of the dismantled mobile teams were, for the most part, appointed to health care facilities in charge of passive screening, thus potentially improving the diagnostic performance of these facilities. In the other provinces, the progressive integration of HAT control and surveillance into the health system has advanced while keeping mobile teams operational.

The sustainability and long term performance of this strategy are faced by numerous threats. It is difficult to replace committed and trained staff in HAT diagnosis and treatment who retire. The loss of the economic incentives associated with active case-finding surveys reduces motivation.

Rapid and effective treatment of newly detected HAT patients is one of the cornerstones of HAT control. Although the topic has not been discussed in the present study, closing down mobile teams and CDTCs may have a dramatic impact on treatment compliance.

A recent survey revealed that 524 fixed health facilities in DRC provide some type of diagnosis for HAT, and that over 30 million people at risk (i.e., $83 \%$ of the total population at risk in DRC) are estimated to live within 5-h travel of such facilities [23]. However, low attendance or 
access to Health Services [24], coupled with lack of screening tools or skilled staff, would suggest that the real coverage may be much lower than the estimated potential coverage. As a result, improved performance of passive detection may not be offsetting the decreased intensity of active screening. If this were the case, recent trends in the number of HAT cases could be biased by an overall reduction in detection capability.

In addition, in 2011 and 2012 the mobile teams still operational have seen their activity reduced by $50 \%$ because of financial constraints, thus resulting in the lowest number of people screened by active case-finding surveys in the study period. Cuts have spared a few mobile teams operating in areas of high transmission, and those involved in research projects.

Specific challenges affect HAT surveillance and control in densely populated areas such as urban Kinshasa, where traditional control strategies may not be adequate and innovative, and adaptive approaches might be needed.

Over the last decade DRC has hosted several clinical trials for the development of new screening, diagnostics and treatment tools. Clinical trials had a positive impact on the NSSCP, which can be measured in terms of new tools, as well as reinforced screening activities and increased capacity and expertise among the staff. However, as clinical trials need tailored plans for recruiting patients, they have at times altered the NSSCP's operational plans. Whilst upgrading health care facilities hosting them, clinical trials have often forgotten to support mobile teams looking for patients, and they have failed to foresee the challenges the sites would face after completion of the trials.

Cases of T. b. rhodesiense sleeping sickness are reported from Kigoma, in the United Republic of Tanzania, only a few kilometres away from the border with DRC. Despite this, the threat of a merger of transmission areas of the two forms of the disease is not as high as in Uganda. Indeed, whereas cattle movement is the major factor for the northern spread of T. b. rhodesiense in Uganda [25], the natural barrier represented by Lake Tanganyika separates the T. $b$. rhodesiense affected areas in Kigoma and the T. $b$. gambiense affected areas in DRC. Although traffic is intense between the two shores of the lake, cattle trade is not involved. In addition, the pattern of $T . b$. rhodesiense transmission in Kigoma is mainly characterized by the wildlife reservoir in a game reserve [26].

\section{Conclusions}

The progressive decrease in HAT cases reported in DRC is likely to reflect a real decline in disease incidence. Nevertheless caution is needed when interpreting the reported figures, because a number of weaknesses characterize the control and surveillance of HAT in both passive and active case detection.
The government strategy to reinforce the national health system, together with the decrease in number of cases in several transmission areas, call for the integration of HAT control and surveillance into the existing health care facilities. However, at this juncture it must be carefully avoided to push forward integration when and where staff are not yet sufficiently skilled or the equipment and monitoring is not assured. There is still a need for both (i) mobile teams, either to tackle areas where intense transmission persists or where passive detection indicates an increase of transmission, and (ii) central structures at provincial and national level, which are needed for technical support (including training), data analysis, planning, monitoring and evaluation of the entire control and surveillance activities at all levels of the health system.

HAT control and surveillance in DRC is still extremely dependent on international aid. Success in controlling HAT in DRC has rested on skilled staff who were committed to providing support to patients, but who were also economically motivated thanks to external funding. Worryingly, during the last years a decrease in external financial support has been observed. Therefore, it seems necessary to question the extent to which the implementation of the present integration strategy is driven by changes in the epidemiological context and by the limited existing capabilities of the national health system, or whether, worryingly, the process is mainly a consequence of financial constraints. Careful assessment and close monitoring and evaluation of the NSSCP strategy in DRC is warranted, in particular in relation to the integration of HAT control and surveillance into a health system widely described as weak. To counter the possible decrease of external funds for HAT control in DRC, it is crucial to increase the ownership of HAT elimination by national health policy makers.

Decentralisation could help the management of the NSSCP, but it also poses challenges when it comes to giving HAT sufficient priority in the annual plans of activities at the provincial level, where competition from other health issues is harsh.

To consolidate the recent achievements in disease control and to avoid negative reversals, it seems urgent to explore alternative and adapted control and surveillance strategies. These may benefit from recently developed screening tools, advances in the development of new oral drugs, and an expectedly more favourable security environment.

The lessons learned in DRC are believed to be valuable for a range of countries affected by gambiense HAT, and they can therefore contribute to reaching the goals of HAT elimination set at the international level [27]. 


\section{Additional files}

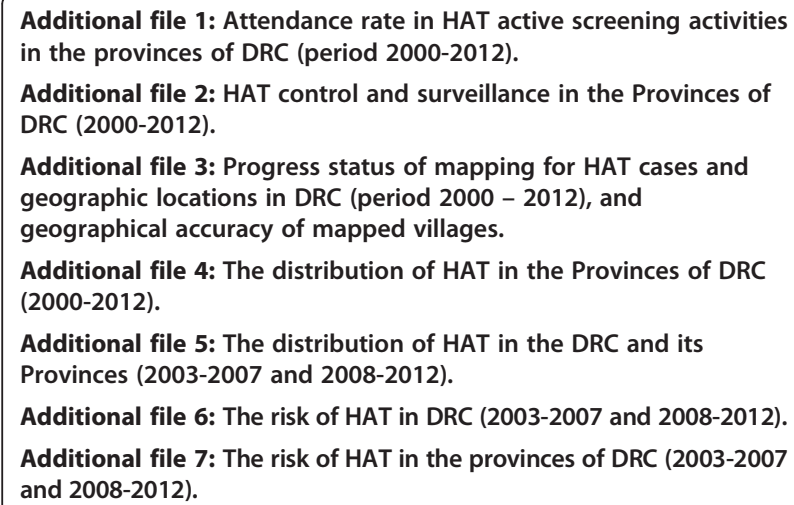

Additional file 3: Progress status of mapping for HAT cases and geographic locations in DRC (period 2000 - 2012), and geographical accuracy of mapped villages.

Additional file 4: The distribution of HAT in the Provinces of DRC (2000-2012).

Additional file 5: The distribution of HAT in the DRC and its Provinces (2003-2007 and 2008-2012).

Additional file 6: The risk of HAT in DRC (2003-2007 and 2008-2012). Additional file 7: The risk of HAT in the provinces of DRC (2003-2007 and 2008-2012).

\section{Abbreviations}

CDTC: Centres for Diagnosis Treatment and Control (Centre de diagnostic traitement et contrôle); DRC: Democratic Republic of the Congo; FAO: Food and Agriculture Organization of the United Nations; GIS: Geographic Information System; GPS: Global Positioning System; HAT: human African trypanosomiasis; MSF: Médecins Sans Frontières; NGO: Non-Governmental Organization; NSSCP: National Sleeping Sickness Control Programme (PNLTHA: Programme Nationale de lutte contre la Trypanosomiasis humaine africaine); PAAT: Programme Against African Trypanosomosis; $T$. b: Trypanosoma brucei; WHO: World Health Organization.

\section{Competing interests}

The authors declare that they have no competing interests.

\section{Authors' contributions}

CL coordinates the NSSCP in DRC. PPS coordinated the HAT Atlas initiative. GC supervised the technical aspects related to data management and GIS. CL, PPS and GC jointly drafted the manuscript. MP implemented geo-positioning procedures and managed the geo-database underpinning the Atlas of HAT. All authors have contributed to conceptualizing the manuscript, and commented on and approved the final draft.

\section{Acknowledgments}

The results presented in this paper were made possible by the daily work and commitment of NSSCP staff in DRC. Without their continuous efforts none of the results presented in this paper would have been possible. Our recognition and admiration goes to all of them and their families, who had to endure long periods of separation during active case finding surveys. This paper was developed in the framework of the Atlas of HAT, an initiative of the Department of Control of Neglected Tropical Diseases-World Health Organization, jointly implemented by WHO and FAO in the framework of the PAAT.

The work of GC was supported by the FAO project "Improving food security in sub-Saharan Africa by supporting the progressive reduction of tsetsetransmitted trypanosomosis in the framework of NEPAD" (GTFS/RAF/474/ITA), funded by the Government of Italy through the FAO Trust Fund for Food Security and Food Safety. Funds for MP's activities were provided by WHO and FAO (Project GTFS/RAF/474/ITA).

\section{Disclaimers}

The boundaries and names shown and the designations used on the maps presented in this paper do not imply the expression of any opinion whatsoever on the part of $\mathrm{WHO}$ and FAO concerning the legal status of any country, territory, city or area or of its authorities, or concerning the delimitation of its frontiers or boundaries. Dotted lines on maps represent approximate border lines for which there may not yet be full agreement. The views expressed in this paper are those of the authors and do not necessarily reflect the views of WHO and FAO. (c) World Health Organization/Food and Agriculture Organization of the United Nations.

\section{Author details}

${ }^{1}$ National Sleeping Sickness Control Programme, Kinshasa, Democratic Republic of the Congo. ${ }^{2}$ World Health Organization, Control of Neglected Tropical Diseases, Innovative and Intensified Disease Management, 1211, Geneva 27, Switzerland. ${ }^{3}$ Food and Agriculture Organization of the United Nations, Sub-regional Office for Eastern Africa, Addis Ababa, Ethiopia. ${ }^{4}$ Food and Agriculture Organization of the United Nations, Animal Production and Health Division, Viale delle Terme di Caracalla, 00153 Rome, Italy. ${ }^{5}$ Neglected Tropical Diseases Department, Ministry of Public Health, Kinshasa, Democratic Republic of the Congo. ${ }^{6}$ World Health Organization, Regional Office for Africa, Intercountry Support Team, Libreville, Gabon.

Received: 1 April 2015 Accepted: 21 May 2015

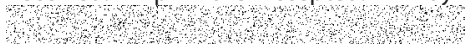

\section{References}

1. Simarro PP, Cecchi G, Paone M, Franco JR, Diarra A, Ruiz JA, et al. The Atlas of human African trypanosomiasis: a contribution to global mapping of neglected tropical diseases. Int J Health Geogr. 2010;9:57.

2. WHO. Technical Report Series. In: Control and surveillance of African trypanosomiasis. Geneva: World Health Organization; 2013. p. 984. http:// apps.who.int/iris/bitstream/10665/95732/1/9789241209847_eng.pdf.

3. WHO. WHO Report on Global Surveillance of Epidemic-prone Infectious Diseases. Geneva: World Health Organization; 2000. Available from: http:// www.who.int/csr/resources/publications/surveillance/ WHO_Report_Infectious_Diseases.pdf?ua $=1$.

4. WHO. Control and surveillance of African trypanosomiasis. Geneva: World Health Organization; 1998. p. 881. Available from: http://whqlibdoc.who.int/ trs/WHO_TRS_881.pdf?ua=1.

5. Van Nieuwenhove S, Betu Ku Mesu VK, Diabakana PM, Declercq J, Bilenge CMM. Sleeping sickness resurgence in the DRC: the past decade. Trop Med Int Health. 2001;6(5):335-41.

6. Lutumba P, Robays J, Miaka mia Bilenge C, Mesu VK, Molisho D, Declercq J, et al. Trypanosomiasis control, Democratic Republic of Congo, 1993-2003. Emerg Infect Dis. 2005;11(9):1382-8.

7. WHO. Report of a WHO meeting on elimination of African trypanosomiasis (Trypanosoma brucei gambiense). Geneva: World Health Organization; 2013. p. 2013. Available from: http://apps.who.int/iris/bitstream/10665/79689/1/ WHO_HTM_NTD_IDM_2013.4_eng.pdf?ua=1.

8. Simarro PP, Cecchi G, Franco JR, Paone M, Diarra A, Priotto G. Monitoring the progress towards the elimination of gambiense human African trypanosomiasis. PLoS Negl Trop Dis. 2015;9(6):e0003785

9. Tong J, Valverde O, Mahoudeau C, Yun O, Chappuis F. Challenges of controlling sleeping sickness in areas of violent conflict: experience in the Democratic Republic of Congo. Confl Health. 2011;5:7.

10. Cecchi G, Paone M, Franco JR, Fèvre E, Diarra A, Ruiz J, et al. Towards the Atlas of human African trypanosomiasis. Int J Health Geogr. 2009;8:15.

11. Ebeja AK, Lutumba P, Molisho D, Kegels G, Miaka mia Bilenge C, Boelaert M. [Sleeping sickness in the region of the town of Kinshasa: a retrospective analysis during the surveillance period 1996-2000]. Trop Med Int Health. 2003:8(10):949-55,

12. Grébaut P, Bena JM, Manzambi EZ, Mansinsa P, Khande V, Ollivier G, et al. Characterization of sleeping sickness transmission sites in rural and periurban areas of Kinshasa (Republique Democratique du Congo). Vector Borne Zoonotic Dis. 2009;9(6):631-6.

13. Robays J, Ebeja Kadima A, Lutumba P, Miaka mia Bilenge C, Kande Betu Ku Mesu V, De Deken R, et al. Human African trypanosomiasis amongst urban residents in Kinshasa: a case-control study. Trop Med Int Health. 2004;9(8):869-75.

14. Tshimungu K, Kalambayi BB, Kiyombo M, Okenge LN, Mol PD. Knowledge, behaviours, practices and beliefs regarding Human African Trypanosomiasis (HAT) among inhabitants of Kinshasa (Democratic Republic of Congo). Sante. 2008;18(3):141-7.

15. De Deken R, Sumbu J, Mpiana S, Mansinsa P, WAT'Senga F, Lutumba P, et al. Trypanosomiasis in Kinshasa: distribution of the vector, Glossina fuscipes quanzensis, and risk of transmission in the peri-urban area. Med Vet Entomol. 2005;19(4):353-9.

16. Simarro PP, Cecchi G, Franco JR, Paone M, Fèvre EM, Diarra A, et al. Estimating and mapping the population at risk of sleeping sickness. PLoS Negl Trop Dis. 2012;6(10):e1859. 
17. Simarro PP, Cecchi G, Franco JR, Paone M, Fèvre EM, Diarra A, et al. Risk for human African trypanosomiasis, Central Africa, 2000-2009. Emerg Infect Dis. 2011;17(12):2322-4.

18. Silverman BW. Density Estimation for Statistics and Data Analysis. New York: Chapman \& Hall; 1986

19. Diggle PJ. Statistical analysis of spatial point patterns. London: Academic; 1983.

20. Bhaduri B, Bright E, Coleman P, Dobson J. LandScan: Locating people is what matters. Geoinformatics. 2002;5(2):34-7.

21. Dobson J, Bright E, Coleman P, Durfee R, Worley B. LandScan: a globa population database for estimating populations at risk. Photogramm Eng Remote Sensing. 2000;66(7):849-57

22. Robays J, Bilengue MM, Van der Stuyft $P$, Boelaert $M$. The effectiveness of active population screening and treatment for sleeping sickness control in the Democratic Republic of Congo. Trop Med Int Health. 2004;9(5):542-50.

23. Simarro PP, Cecchi G, Franco JR, Paone M, Diarra A, Ruiz-Postigo JA, et al. Mapping the capacities of fixed health facilities to cover people at risk of gambiense human African trypanosomiasis. Int J Health Geogr. 2014;13:4.

24. Wembonyama S, Mpaka S, Tshilolo L. Medicine and health in the

Democratic Republic of Congo: from Independence to the Third Republic. Med Trop (Mars). 2007;67(5):447-57.

25. Fèvre EM, Coleman PG, Odiit M, Magona JW, Welburn SC, Woolhouse ME. The origins of a new Trypanosoma brucei rhodesiense sleeping sickness outbreak in eastern Uganda. Lancet. 2001;358(9282):625-8.

26. Simarro P, Franco J, Diarra A, Ruiz Postigo J, Jannin J. Diversity of human African trypanosomiasis epidemiological settings requires fine-tuning control strategies to facilitate disease elimination. Research and Reports in Tropical Medicine. 2013:4:1-6.

27. WHO. Resolution 66.12. Neglected Tropical diseases. Geneva, Switzerland World Health Organization; 2013. Available from: http://www.who.int/ neglected_diseases/mediacentre/WHA_66.12_Eng.pdf.

\section{Submit your next manuscript to BioMed Central and take full advantage of:}

- Convenient online submission

- Thorough peer review

- No space constraints or color figure charges

- Immediate publication on acceptance

- Inclusion in PubMed, CAS, Scopus and Google Scholar

- Research which is freely available for redistribution 